This item is the archived peer-reviewed author-version of:

Environmental factors influencing beaver dam locations

\title{
Reference:
}

Sw innen Kristijn, Rutten Anneleen, Nyssen Jan, Leirs Herw ig.- Environmental factors influencing beaver dam locations

Journal of wildlife management - ISSN 0022-541X - 83:2(2019), p. 356-364

Full text (Publisher's DOI): https://doi.org/10.1002/JWMG.21601

To cite this reference: https://hdl.handle.net/10067/1564050151162165141 
1 Swinnen \& Rutten et al.

Reference: Swinnen K.R.R, Rutten A., Nyssen J., Leirs H. 2018. Environmental factors influencing beaver dam locations. The Journal of Wildlife Management 2018, 83(2), 356364

\section{Environmental Factors Influencing Beaver Dam Locations}

KRISTIJN R. R. SWINNEN, ${ }^{1,2}$ Evolutionary Ecology Group, Biology Department, University of Antwerp, Universiteitsplein 1, 2610 Wilrijk, Antwerpen, Belgium

ANNELEEN RUTTEN, ${ }^{2}$ Evolutionary Ecology Group, Biology Department, University of Antwerp, Universiteitsplein 1, 2610 Wilrijk, Antwerpen, Belgium

JAN NYSSEN, Department of Geography, Ghent University, Krijgslaan 281, 9000 Gent, Belgium

HERWIG LEIRS, Evolutionary Ecology Group, Biology Department, University of Antwerp, Universiteitsplein 1, 2610 Wilrijk, Antwerpen, Belgium

ABSTRACT Beavers are known for their ability to build dams that change the environment.

They also occupy territories where they do not construct dams. The goal of this study was to determine which environmental factors influence beaver dam construction and to examine the upstream water level increase caused by the dams. We compared factors collected at 15 beaver territories with dams (32 dams) and 13 territories without dams (i.e., control) in the gently undulating and human-dominated landscape of Middle Belgium in 2013. River width, river depth, distance from woody vegetation, stream velocity, and bank height differed significantly between territories with and without dams. Water depth was the most important parameter to correctly classify territories as either dam territory or control territory (with 97\%

\footnotetext{
${ }^{1}$ Email: kristijn.swinnen@natuurpunt.be

${ }^{2}$ Equal contributions.
} 
2 | Swinnen \& Rutten et al.

accuracy). When beavers were present and water depth in summer was $<68 \mathrm{~cm}$, the probability of dam building was high; if water depth was $>68 \mathrm{~cm}$, dam building was unlikely. Dams caused an increase in the upstream water level of on average $47 \pm 21 \mathrm{~cm}$. On average the water level could rise only an additional $25 \pm 30 \mathrm{~cm}$ upstream of the dam before bank overtopping would occur. These results provide a simple tool for planners to assess the probability of floodplain inundation by beaver dam building, as part of multifunctional riverine landscape management.

KEY WORDS beaver dam, Belgium, Castor fiber, ecosystem engineer, Eurasian beaver, prediction model.

Once widespread throughout forests and wooded river valleys of Europe and Asia, by the beginning of the twentieth century only about 1,200 Eurasian beavers (Castor fiber) remained in 8 small relict populations (Nolet and Rosell 1998). Over-hunting for fur, meat, and castoreum was the main reason for this decline (Nolet and Rosell 1998). However, translocations, natural spread, and reduced persecution have allowed populations to recover to over 1 million individuals (Halley et al. 2012), with beavers now re-established throughout most of their former range including Flanders, Belgium (Halley et al. 2012).

By building dams, digging, burrowing, foraging, and cutting trees beavers can cause considerable environmental changes (Jones et al. 1994; Wright et al. 2002; Rosell et al. 2005; Nyssen et al. 2011; Hood and Larson 2014). As a result, beavers are often considered ecosystem engineers because they can change, maintain, or create habitats by modulating the availability of both biotic and abiotic resources for themselves and for other species (Rosell et al. 2005). Beavers may occur in a variety of lentic and lotic environments, from small seepages and ponds, to large rivers and lakes. However, dams are not built in all beaver territories (Hartman and Tornlov 2006). 
3 | Swinnen \& Rutten et al.

Although dams fulfil multiple purposes, all increase the water level upstream of the dam, creating a beaver pond. A beaver pond makes it possible for the beavers to construct a burrow or lodge with an underwater entrance, which reduces predation risk (Gurnell 1998, Hartman and Axelsson 2004, Rosell et al. 2005) and can be used to cache food for winter (Hartman and Axelsson 2004, Beck et al. 2010). Additionally, the increase in water level associated with beaver dams may change the position of the edge of the beaver pond, allowing easier access to food sources because beavers prefer to forage within $10 \mathrm{~m}$ of water (Nolet et al. 1994, Hartman and Tornlov 2006).

Beaver dams can increase the area of riparian habitat by flooding the surrounding area and elevating the water table (Johnston and Naiman 1987). However, flooding is not always desirable in human-dominated landscapes and may cause human-wildlife conflicts (Mitchell 2003, Pahl-Wostl 2006, Kellens et al. 2013). The building of dams, and the consequential possible flooding of agricultural land and even nature reserves (where they can disturb nutrient cycles with nutrient-rich river water [not frequently reported]), is the main concern regarding the return of the beaver in Flanders, Belgium (G. Van Hoydonck, Agency for Nature and Forest Conservation, personal communication). Removing beaver dams, which requires a permit because of the strict protection status given to beavers in Flanders, is only a short-term solution to disturbance caused by beavers if the beavers themselves are not removed because dams will quickly be reconstructed. Alternatively, dams and water levels can be managed by flow devices (Lisle 2003, Taylor and Singleton 2014, Campbell-Palmer et al. 2016). However, beaver presence and beaver dams can also provide services contributing to river and wetland restoration and catchment management (Burchsted et al. 2010, De Visscher et al. 2014), which fits closely with goals of the European Water Framework Directive (Pahl-Wostl 2006). For example, beavers can assist in augmenting water tables, 
4 | Swinnen \& Rutten et al.

increasing summer base flows, expanding wetlands, improving water quality, and increasing habitat complexity (Pollock et al. 2018).

Considering the effect that beaver dams have on the surrounding landscape, it is important to understand the environmental conditions that influence dam building (Hartman and Tornlov 2006). Only a few studies have investigated the factors influencing dam building by Eurasian beavers (Hartman and Tornlov 2006) and the Canadian beaver (Castor canadensis; McComb et al. 1990, Barnes and Mallik 1996, Suzuki and McComb 1998). The majority of these studies compared dam sites with unoccupied sites (McComb et al. 1990, Barnes and Mallik 1996, Suzuki and McComb 1998), although dam building factors are not necessarily the same as habitat selection factors. Although the study by Hartman and Tornlov (2006) on beaver dam construction in Sweden reported that water depth and stream channel width are good discriminatory measures when comparing between dam and control sites in a more mountainous region, the extent to which this is true for lowland landscapes has not yet been explored.

We aimed to determine which environmental factors influence Eurasian beaver dam building behavior in a gently undulating and human-dominated lowland in Flanders. We expected that water depth, stream channel width, stream velocity, distance to woody vegetation, woody vegetation coverage, bank height, and bank slope would be important factors that influenced dam building. We also studied the effects of beaver dam building on upstream water depth and bank overtopping.

\section{STUDY AREA}

The studied riverscape comprised first- to third-order permanent rivers at the southern margins of the continental North Sea plains in northwest Europe (Middle Belgium and Southern Netherlands), with a temperate maritime climate (mean rain depth of $800 \mathrm{~mm} / \mathrm{yr}$ with moderate summers and mild winters) and a gently undulating landscape (elevation 
5 | Swinnen \& Rutten et al.

between 0 and $288 \mathrm{~m}$ ). Lithology comprised soft sedimentary rocks deposited from late Mesozoicum to late Tertiary. We avoided collecting data in the valleys in the hard Palaeozoic rocks of the Ardennes-Eifel massif more to the south because these valleys were constricted, there was near-absence of floodplains, and human population density was low and concentrated in more elevated places; therefore, the direct effect of high beaver dam densities on humans was limited. The core area, Flanders region in Belgium, was $13,522 \mathrm{~km}^{2}$ and densely populated (462 inhabitants/ $\mathrm{km}^{2}$; Statbel 2010). Dominant land use was agriculture (51\%), urban areas (30\%), and nature (protected and unprotected, mainly woodland (temperate forests) 10\%, water 2\%, and semi-natural grassland 1\%); Vriens et al., 2011). Apart from Eurasian beavers, other larger mammals in the study area were foxes (Vulpes vulpes), badgers (Meles meles), roe deer (Capreolus capreolus), red deer (Cervus elaphus, mainly in the south of the study area) and wild boar (Sus scrofa). and at least two wolfs (Canis lupus) in a recent settlement after more than a century of absence (K.S. unpublished information). We collected data at all known beaver territories in Flanders in the northern part of Belgium, and 3 adjacent territories in the Walloon region of Belgium and 1 territory in the Netherlands. The beaver population of this area, 71 territories at the time of this study (Swinnen et al. 2017), originated from reintroduction in 2003 and immigration from neighboring regions. Swinnen et al. (2017) estimated that there was sufficient habitat to potentially support 924 beaver territories. In 2018, there were an estimated 150 beaver territories occupied in Flanders (K. R. R. Swinnen, University of Antwerp, unpublished information). 
6 | Swinnen \& Rutten et al.

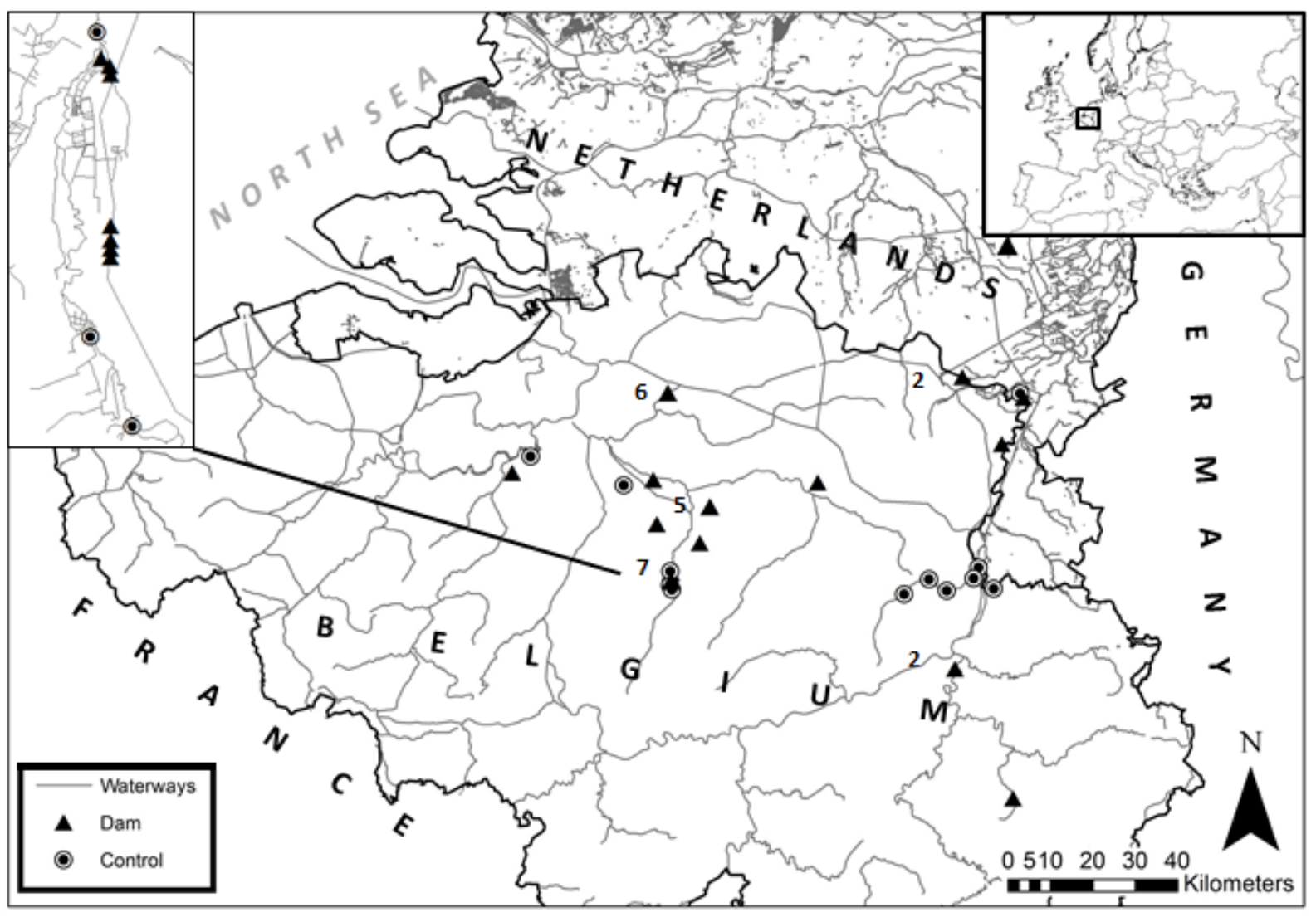

121

Figure 1. Beaver territories sampled in Middle Belgium and The Netherlands (Jul-Oct 2013).

We recorded environmental measurements at 32 dams in 15 territories and at 13 territories

without dams. Places with multiple dams are marked by the number of measured dams in these sites. The territories around the Dijle River are shown in detail because they consist of dams and areas without dams.

\section{METHODS}

\section{Field Methods}

We collected data at 32 dams (all known dams in Flanders in 2013 were included) and 13 territories where beavers had settled but no dams were built (Fig. 1). The 32 dams originated from 15 different territories (6 of these territories include multiple dams). We considered beaver dams within a territory to be independent when they were situated in different waterways. Seven of the 32 dams were equipped with a flow device (i.e., a pipe through the 
7 | Swinnen \& Rutten et al.

beaver dam to reduce the water to a level acceptable for human land use yet still suitable for beavers) by waterway managers to mitigate conflicts with other land use functions. We excluded these 7 dams in the dam effect analysis (Appendix A, available online in Supporting Information). We selected the 13 territories without dams based on knowledge concerning the location of burrow or lodge and their location next to a flowing waterway. We considered these 13 sites to be independent because they were all situated in different territories but were sometimes located on the same waterway. This possibly introduced spatial autocorrelation; therefore, in the dam occurrence analysis (see below) we also compared dam territories with a reduced control territory dataset ( $n=9$ vs. $n=13$ ), only allowing the most upstream and downstream territory per waterway, increasing the distance between territories and reducing the spatial correlation.

We collected data from July-October 2013 to minimize the effects of variable rainfall on flow conditions. Every $10 \mathrm{~m}$ along a bank length of $100 \mathrm{~m}$, we measured water depth, stream width, and bank profile at both banks. In territories without dams, we measured from $50 \mathrm{~m}$ upstream to $50 \mathrm{~m}$ downstream starting from the beaver burrow or lodge. In dam territories, we recorded measurements for $100 \mathrm{~m}$ downstream and upstream of the dam. We considered the measured strip downstream of the dam to be representative of the stream before the dam was built, whereas the strip upstream represented the effect of the dam. We measured water depth, stream width, and bank profile in both confluent waterways when a confluence was present within the measured range.

We measured water depth in the middle of the stream, at $1 \mathrm{~m}$ to the left, and at $1 \mathrm{~m}$ to the right of the middle. We measured the depth with a measuring rod from the water surface to the bottom of the stream without pushing into the sediment; we recorded a second measurement by pushing the rod into the sediment down to the solid bottom to measure the sediment depth. We measured stream channel width with a tape measure from bank to bank at 
8 | Swinnen \& Rutten et al.

159

160

161

162

163

164

165

166

167

168

169

170

171

172

173

174

175

176

177

178

179

180

the water surface (Fig. 2). We measured bank profiles at both banks using 3 measurements (Fig. 2). We determined the knickpoint (i.e., transition from sloping bank to flat bottom) by checking the bottom on foot on both sides. We then measured the horizontal distance from the knickpoint to the bank, measured at the water surface $(\mathrm{KB})$, the vertical distance from the water surface at the knickpoint to the top of the bank (HKT), and the horizontal distance from the knickpoint to the top of the bank (KT). We made the latter measurement with a measuring tape on a vertically held rod with a bubble level.

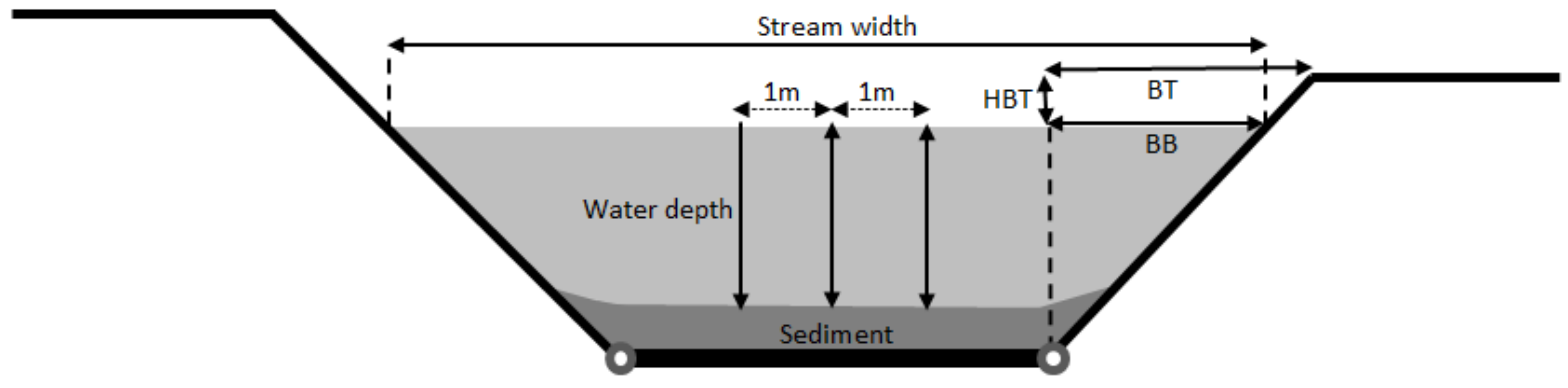

Figure 2. Measurements of bank profile for beaver dam territories and territories without dam construction in Middle Belgium and The Netherlands (Jul-Oct 2013). Water depth is measured in the middle, $1 \mathrm{~m}$ left of the middle, and $1 \mathrm{~m}$ right of the middle of the waterway as the distance from the water surface to the top of the sediment layer. Stream width is measured from bank to bank at the water surface. The bank profile is determined by 3 measurements (measured at the left and right river bank, shown only once in the figure): the distance from the knickpoint (white dot) to the river bank, measured on the water surface (KB), the horizontal distance from the top of the bank to the knickpoint (KT), and the vertical distance from the top of the bank to the water surface (HKT).

In all territories, we measured the distance from the dam (or burrow) to the nearest woody vegetation (1-m accuracy) because the presence of woody vegetation could influence the construction of a dam near the burrow. We estimated stream velocity based on 3 
9 | Swinnen \& Rutten et al.

181

182

183

184

185

186

187

188

189

190

191

192

193

194

195

196

197

198

199

200

201

202

203

204

measurements of the time ( 0.1 seconds accuracy) that a floating object (a piece of cork or a small branch) needed to move 1-10 $\mathrm{m}$ (we used smaller distances for slow flowing rivers) $\geq 20 \mathrm{~m}$ downstream of the dam or near the burrow in territories without a dam, in the middle on a straight river segment.

We calculated the percentage of woody vegetation around the dam or burrow (a strip of $50 \mathrm{~m}$ up- to downstream, within $15 \mathrm{~m}$ from the bank) in ArcGIS (version 10.0,

Environmental Systems Research Institute, Redlands, CA, USA) from infra-red aerial photographs (Agency for Geographical Information Flanders, Ghent, Belgium, summer 2012; resolution of $0.1 \mathrm{~m}$ ) using supervised maximum likelihood classification. Resultant classes were water, woody vegetation, and non-woody vegetation.

We measured the difference in water level upstream and downstream of the dam at 2 locations on the dam by holding a measuring rod horizontal over the dam (controlled with a bubble level) and measuring the distance from the rod to the water surface on both sides of the dam. When a confluence was present within the measuring strips of dams $(n=10)$, we measured the distance from a dam to the nearest confluence down and upstream using ArcGIS following the curves of the streams.

\section{Data Analysis}

We obtained 3 measurements of water depth (left, middle, and right) per measuring location. Preliminary analyses indicated that differences in water depths per measuring location were not statistically significant (analysis of variance [ANOVA]; $P=0.36, F_{2}=1.03$ ), so we averaged values and used a single value of water depth for further analysis. Because we did not detect differences in water depth (paired $t$-test; $P=0.18, t_{10}=-1.46$ ) or water width (paired $t$-test, $P=0.75, t_{10}=0.33$ ) at confluent streams, we averaged measurements at confluent streams. 
10 | Swinnen \& Rutten et al.

Analyzing dam presence.-We tested for differences between dam territories and

territories without a dam based on 7 environmental conditions: water depth and width at $10 \mathrm{~m}$

207

208 downstream of the dam or burrow (in territories with multiple dams, we took these measurements downstream of the last dam); distance from the dam or burrow to nearest woody vegetation; stream velocity; average bank height (sum of sediment depth, water depth, and the height from the water surface to top of the bank; Fig. 2) and slope (tangent of the angle between the bank height and the distance from the knickpoint at the water surface until the bank; Fig. 2) from $50 \mathrm{~m}$ upstream to $50 \mathrm{~m}$ downstream of the dam or burrow; and the percentage of woody vegetation. For territories with multiple dams, we considered only the oldest dam for distance to vegetation, stream velocity, average bank height, bank slope, and percentage of woody vegetation. We included dams with a flow device because a flow device does not influence original environmental conditions that determined dam construction. We compared the resulting 18 territories with a dam (Appendix A) to 13 territories without using $t$-tests or Wilcoxon tests.

We analyzed the difference in environmental conditions between sites with and without a dam using a binomial logistic regression model for each of these environmental conditions. For each, we calculated a threshold value as determinant for the presence or absence of a dam. We defined this threshold as the point at which both specificity (true negative rate) and sensitivity (true positive rate) of the regression model was maximized (Guisan and Zimmerman, 2000).

Next, we constructed a classification tree, which allowed us to determine how many and which environmental variables are needed to best discriminate between sites with and without a dam. Conditional inference trees are non-parametric regression trees in treestructured regression models embedding recursive binary partitioning. Using the ctree function (package Party version 1.0-21, R statistics; Hothorn et al. 2006) in repeating steps, 
11 Swinnen \& Rutten et al.

230

231

232

233

234

235

236

237

238

239

240

241

242

243

244

245

246

247

248

249

250

251

252

253

254

we tested the dependence between input and response variables; we selected the input variable with the strongest association to the response variable after which we defined a binary split of the selected input variable. Next, we repeated these steps until we could find no more dependence between remaining input- and response variables. We examined the effect of confluences on the probability of dam building by comparing the distance to the confluence upstream to the distance of the nearest confluence downstream of the dam (Wilcoxon test, $n=$ $10)$.

Analyzing dam effects. - We excluded dams with flow devices from this analysis. We analyzed series of dams as if they consisted of 1 dam, using the upstream measurements of the most upstream dam and the downstream measurements of the most downstream dam. This resulted in 16 dams appropriate for use in this analysis. We calculated the increase of the water level by averaging the 2 measurements of the difference of the water level just upstream and downstream the dam. We calculated the upstream lowest bank height per dam because bank overtopping (and flooding) will start from this point. We compared the change in water depth and stream width between downstream and upstream of the dam (Wilcoxon test). We conducted all statistical analyses in R (version 3.1.2, The R Foundation for Statistical Computing, Vienna, Austria).

\section{RESULTS}

\section{Dam Occurrence}

Comparison of environmental conditions between territories with and without dams showed significant differences for stream width (dam locations were narrower, $t$-test; $P<0.001, t_{14.60}$ $=-4.50$ ), water depth (dam locations were shallower, Wilcoxon test; $P<0.001, W=3$ ), distance from vegetation (dam locations were closer to woody vegetation, Wilcoxon test; $P$ $=0.004, W=29.5$ ), stream velocity (lower near dam locations, $t$-test; $P=0.002, t_{12.25}=-4.04$ ), and bank height (lower near dam locations, $t$-test; $P=0.002, t_{13.45}=-3.86$ ). Differences in 
12 | Swinnen \& Rutten et al.

255 bank slope ( $t$-test; $\left.P=0.26, t_{24.20}=1.15\right)$ and the percentage of woody vegetation $(t$-test, $P$

$\left.256=0.66, t_{25.99}=-0.44\right)$ were not significant. When comparing dam territories with the reduced

257 dataset of control territories for spatial autocorrelation analysis (leaving out multiple

258 territories in the same waterway), $P$-values increased, but tests that were significant in the full 259 dataset were also significant in the reduced set. 
13 | Swinnen \& Rutten et al.
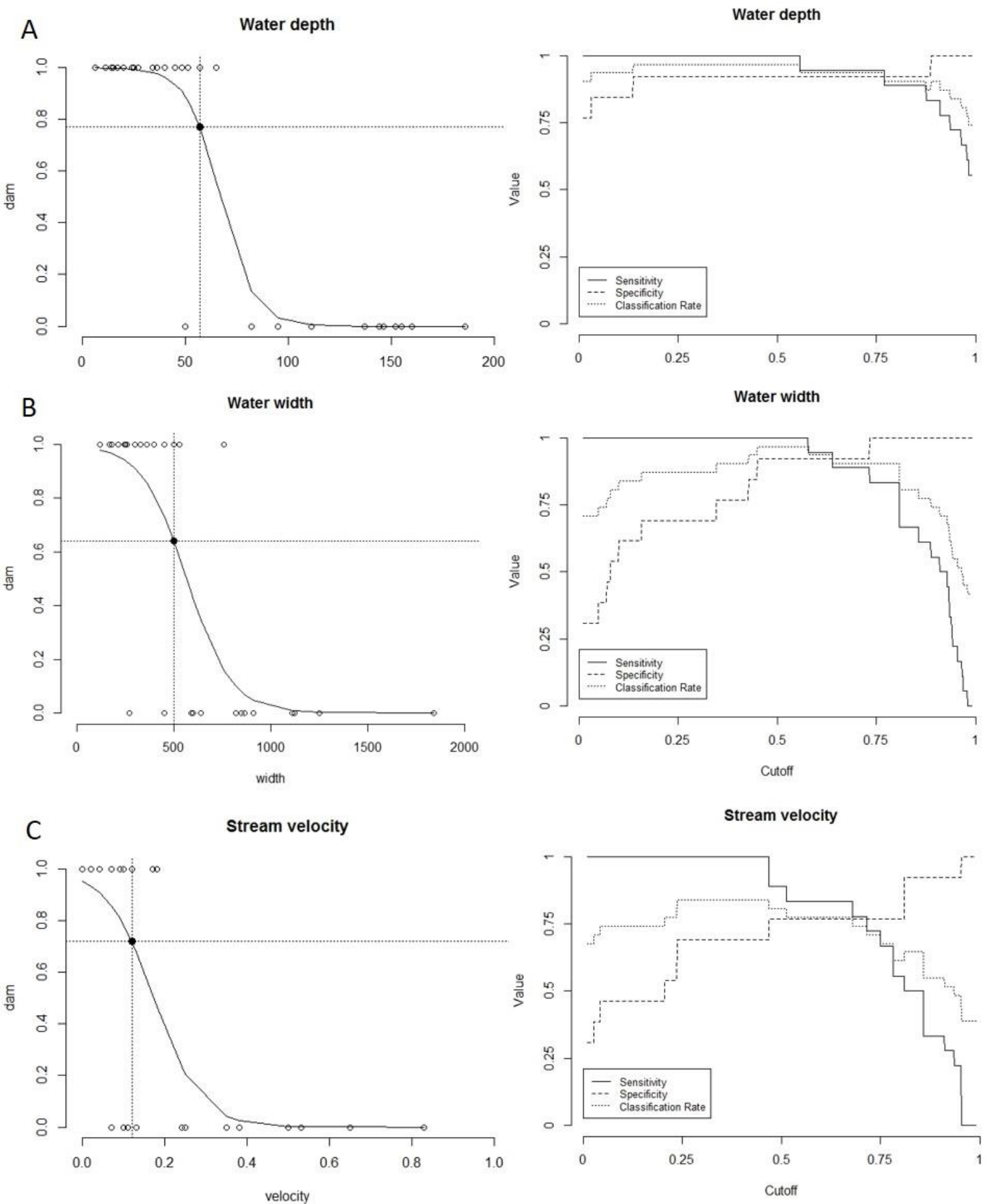
14 | Swinnen \& Rutten et al.
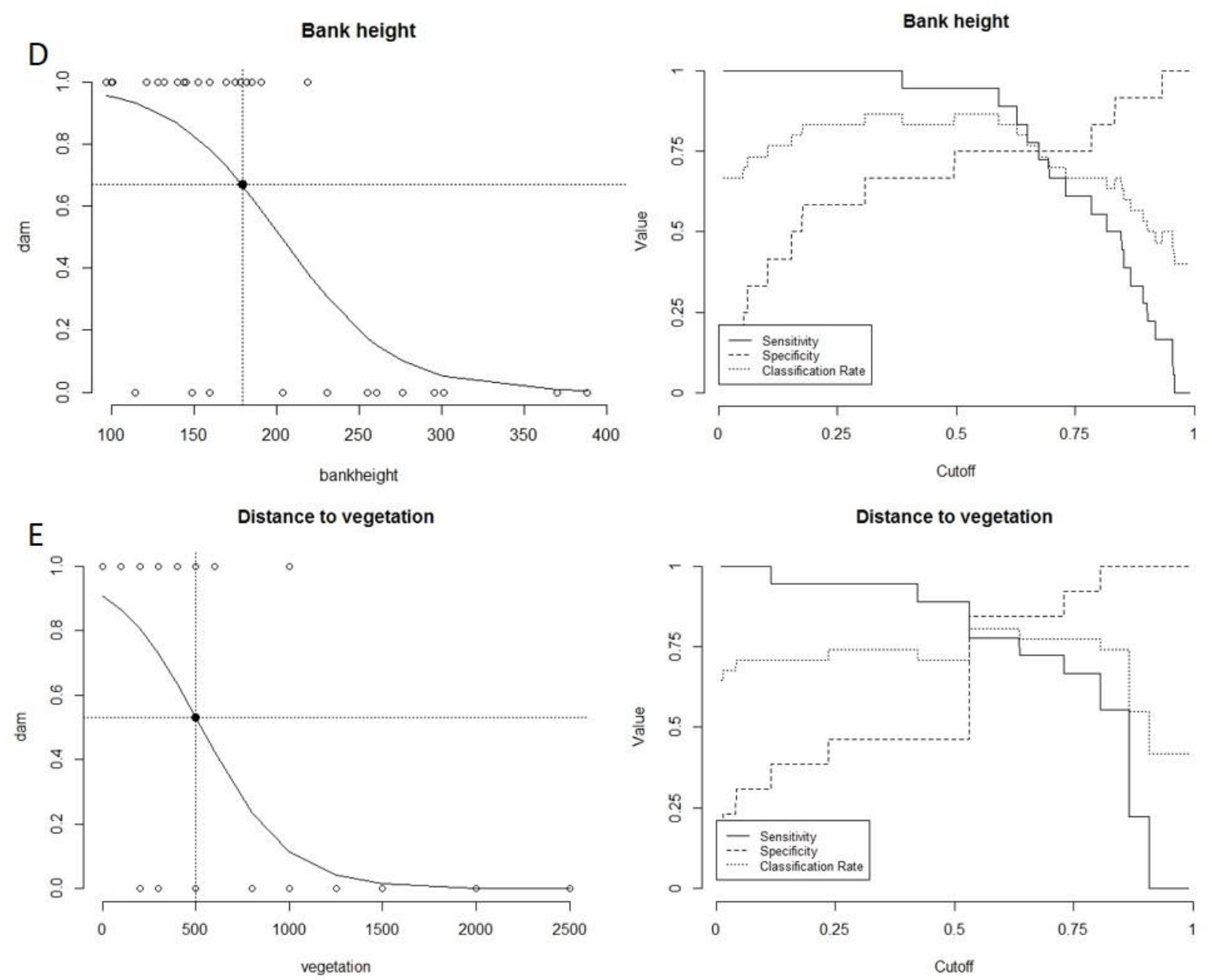

Figure 3. Binomial distribution graphs of the 5 environmental conditions, measured in Middle Belgium and The Netherlands (Jul-Oct 2013), that are determinant of a waterway being suitable for dam construction by beavers together with specificity-sensitivity graphs of each binomial model: water depth (cm) at $10 \mathrm{~m}$ downstream of the dam, burrow, or lodge; water width (cm) at $10 \mathrm{~m}$ downstream of the dam or at the burrow or lodge; stream velocity $(\mathrm{cm} / \mathrm{second})$; average bank height $(\mathrm{cm})$ from $50 \mathrm{~m}$ downstream to $50 \mathrm{~m}$ upstream of the dam, burrow, or lodge; and distance from dam, burrow, or lodge to nearest woody vegetation (m). Response variables are presence of a dam (1) or the absence of a dam (0). Threshold values are indicated by the dashed lines. 
15 | Swinnen \& Rutten et al.

The binomial plots of the 5 significant environmental factors show a clear distinction between dam territories and territories without dams (Fig. 3). Treshold in these binomial plots values are based on maximizing sensitivity and specificity (Table 1) so false positive and false negative predictions of dam territories are minimized.

The classification tree revealed that based on water depth only, we can distinguish between territories with and without dams with $97 \%$ certainty. The classification tree indicated that when the water depth in a waterway is $<68 \mathrm{~cm}$, a dam is highly likely to be built; when water depth is $>68 \mathrm{~cm}$, it is less likely that a dam will be built. Further inclusion of other parameters did not result in an improved model, resulting in this simple tree with just 1 branching point. When using the reduced control territories dataset, water depth remained the single-most important discrimination parameter, and the threshold remained at $68 \mathrm{~cm}$. The threshold value of water depth calculated based on the classification tree deviated from the threshold calculated based on the binomial function when maximizing model specificity and sensitivity $(68 \mathrm{~cm}$ vs. $57 \mathrm{~cm})$. This can be explained because the thresholds of the classification tree are based on recursive partitioning needed to develop the classification tree in which all the environmental conditions are connected (Hothorn et al. 2006). Thus, the threshold value derived from the classification tree is more relevant because it also takes into account the other environmental variables in contrast to the threshold based on the specificitysensitivity analysis where every variable is analyzed separately.

An upstream confluence was situated on average $37.5 \pm 25.5 \mathrm{~m}$ (SE) from the dam, a downstream confluence on average $510 \pm 170 \mathrm{~m}$ from the dam. So, dams are preferably built downstream of a confluence if present $(P<0.01$, Wilcoxon test $)$. 
16 | Swinnen \& Rutten et al.

Table 1. Cutoff values (0-1) based on maximizing the specificity and the sensitivity of each binomial model separate for each of the 5 environmental conditions measured at beaver dam territories and territories without dam construction in 27 territories in Middle Belgium and 1 in The Netherlands (Jul-Oct 2013), together with their according threshold values. The cutoff values define the threshold values which minimizes false positive and false negative predictions of dam territories. In the reduced dataset 4 territories are removed, only allowing the most upstream and downstream territory per waterway to reduce potential spatial autocorrelation

\begin{tabular}{lcccc}
\hline Environmental condition & $\begin{array}{c}\text { Cutoff } \\
\text { value }\end{array}$ & $\begin{array}{c}\text { Threshold } \\
\text { valus }\end{array}$ & $\begin{array}{c}\text { Cutoff } \\
\text { value } \\
\text { reduced } \\
\text { dataset }\end{array}$ & $\begin{array}{c}\text { Threshold value } \\
\text { reduced dataset }\end{array}$ \\
\hline Water depth (cm) & 0.77 & 57 & 0.80 & 56.5 \\
Water width (cm) & 0.64 & 500 & 0.67 & 498 \\
Flow velocity (cm/s) & 0.72 & 0.12 & 0.74 & 0.115 \\
$\begin{array}{l}\text { Bank height (cm) } \\
\begin{array}{l}\text { Distance to woody vegetation } \\
(\mathrm{m})\end{array}\end{array}$ & 0.67 & 179 & 0.75 & 169 \\
\hline
\end{tabular}

\section{Effects of the Dam}

The difference in water depth upstream and downstream of a dam (averaged over 5-100 m upstream or downstream) was significant (Wilcoxon test, $P<0.01, \mathrm{~W}=66$ ). Average water depth $10 \mathrm{~m}$ upstream of the dam was $93 \pm 30 \mathrm{~cm}($ range $=43-175 \mathrm{~cm}) ; 10 \mathrm{~m}$ downstream of the dam, average water depth was $30 \pm 17 \mathrm{~cm}$ (range $=3-65 \mathrm{~cm})$.

The difference between upstream and downstream stream width (averaged over 5-100 $\mathrm{m}$ upstream or downstream) was also significant $\left(t\right.$-test, $\left.P<0.001, t_{10}=9.47\right)$. Water width 10 $\mathrm{m}$ upstream of the dam was $502 \pm 142 \mathrm{~cm}($ range $=300-780 \mathrm{~cm}) ;$ water width $10 \mathrm{~m}$ downstream of the dam was $339 \pm 165 \mathrm{~cm}($ range $=120-300 \mathrm{~cm})$.

An average increase in the water level of $47 \pm 21 \mathrm{~cm}($ range $=15-87 \mathrm{~cm})$ was caused by dams. The average of the lowest bank height upstream of the dam was $25 \pm 30 \mathrm{~cm}$ (ranging from $-29 \mathrm{~cm}$ [overflow of bank top by $29 \mathrm{~cm}$ of water] to $96 \mathrm{~cm}$ ) higher than the current water level upstream of the dam. The standard deviation was larger than the average value 
$17 \mid$ Swinnen \& Rutten et al.

because at flooded locations, the distance from the water level to the top of the dam was expressed as a negative value.

\section{DISCUSSION}

Hartman and Thornlov (2006) investigated the influence of watercourse depth and width on beaver dam-building in Sweden and were able to discriminate between lodge and dam sites in $93 \%$ of the cases. We tested the importance of these parameters in a different landscape, and included 5 additional environmental parameters to achieve an even better classification. The additional parameters (stream velocity; distance from dam, burrow, or lodge to nearest woody vegetation; bank height) all differed significantly between dam sites and control sites, but they did not increase the power of the classification tree. The best classification tree included only water depth, with a correct classification of $97 \%$ using a threshold water depth of $68 \mathrm{~cm}$, indicating that other parameters result in negligible improvements to classification results. Although the study area of Hartman and Tornlov (2006) and this study area were $>1,000 \mathrm{~km}$ apart and topographically different, we obtained similar results, indicating the robustness of the results and the importance of water depth for beavers deciding to build dams. This also suggests that parameters that were not included like stem diameter of surrounding vegetation, watershed area, and gradient (Barnes and Mallik 1997) would be unlikely to substantially improve the model. We reported similar dam effects on water level; beaver dams increased the water level by an average of $47 \pm 21 \mathrm{~cm}$ in our study area, which is almost identical to the $46 \pm 21 \mathrm{~cm}$ reported by Hartman and Tornlov (2006). Concerning the risk of flooding, on average, the lowest point in the riverbank is only $25 \mathrm{~cm}$ higher than the water level upstream of the dam. This indicates that additional building up of the dam, or peak volumes of water could quickly cause flooding and possibly a human-wildlife conflict.

Because we recorded measurements during summer, the driest time of the year, we did not account for intra-seasonal variability. However, the water level at this point is critical for 
18 | Swinnen \& Rutten et al.

whether dams are constructed because water level is lowest in summer and dams can maintain water levels during low summer flows and reduce seasonal variability (Gurnell, 1998). During periods with more precipitation (from autumn to late spring), natural water levels often are even higher than the dams (K. R. R. Swinnen, Antwerp University, unpublished data ). Of the 13 control territories, different territories were sometimes located on the same waterway, possibly inducing spatial autocorrelation. But when we compare the threshold values using cutoff values for all 13 control territories with the reduced set of control territories that included only the farthest up- and downstream territory per waterway, we found only minor differences. Therefore, we concluded that spatial autocorrelation did not influence our results.

We found that when a confluence is present in an area suitable for dam building, it will be highly likely that the dam will be constructed downstream of this confluence. When constructing a dam downstream of a confluence, only a single dam has to be constructed to increase the water level in both upstream river segments. We suggest that it might be energetically more efficient for beavers to construct and maintain a single dam instead of 2 , even though the risk of this dam being washed out during peak volumes of water could be higher. Alternatively, it could also be less energetically expensive to construct and maintain multiple dams, but this strategy was not favored by beavers. We suggest this is examined further. In addition to the location of a confluence, human intervention, namely the construction of a flow device to manage the conflicting effects of the dam and reduce the water level (Lisle 2003), can have an effect on the location of additional dams. In 3 out of 5 locations where these devices were applied, beavers built multiple dams after installation of the device.

Although dam building can be incompatible with other land use types, beaver presence and their dams can also be integrated in the current policy to ecologically restore waterways 
19 | Swinnen \& Rutten et al.

370

371

372

373

(Pahl-Wostl 2006). The vital role of beaver dams in maintaining and diversifying streams and riparian habitat has been recognized (Rosell et al. 2005, Pollock et al. 2018). Beavers can increase water retention, base flow, and groundwater recharge; decrease peak flows; increase sediment retention; and affect water temperature, nutrient cycling, contaminants, and geomorphology (Rosell et al. 2005, Pollock et al. 2018). Furthermore, beavers can cause changes in abundance and species richness of plants, invertebrates, amphibians, reptiles, fish, birds, and mammals (Collen and Gibson 2001, Rosell et al., 2005, Dalbeck et al. 2007, Nummi and Hahtola 2008, Stringer and Gaywood 2016). Law et al. (2017) documented the results of a planned beaver-assisted habitat restoration from a degraded agricultural area to a wetland with consequential increases in plant heterogeneity, species numbers, and species richness. Beaver dams are considered so useful for river restoration that beaver dam analogues, artificial constructions intended to mimic beaver dams, are used to restore waterways (Pollock et al. 2018).

\section{MANAGEMENT IMPLICATIONS}

The critical threshold of a water depth of $68 \mathrm{~cm}$ makes it possible to predict whether beaver dams will be constructed, and evaluate the possible effects for this location. Dams can affect habitat restoration but can also be undesirable at certain locations. With ongoing dispersal, and the large availability of suitable habitat throughout Flanders (Swinnen et al. 2017), it is likely that additional habitat will be colonized that requires the construction of a dam.

Therefore, we expect the number of beaver dams to increase in Flanders. Water depth is an easy to measure parameter for field managers. Our results can be used to prioritize the monitoring of areas where dam building is likely. Furthermore, this knowledge can also be applied when installing flow devices (Lisle 2003). We also suggest that a minimum water depth of $68 \mathrm{~cm}$ upstream of the dam is conserved during the dry period of the year when using a flow device, which would minimize the necessity for beavers to construct additional dams. 
20 | Swinnen \& Rutten et al.

395

396

397

398

\section{ACKNOWLEDGMENTS}

We thank Natuurpunt and the Agentschap voor Natuur en Bos for facilitating the access to beaver territories and S. Van Dongen for statistical support. Special thanks to G. Coninx, K. de Cock, K. Derks, J-P. Facon, V. Geenens, N. Goossens, J. Peeters, and G. and D.

Vanautgaerden for providing access and valuable field information. We acknowledge the help of D. Dauwe, B. Duwé, M. Haagdorens, E. Herrebosch, J. Rutten, R. Rutten, K. Sprangers, S. Teppers, R. Thuys, A. Van Mensel, and L. Quirinjean during field work. A final thanks to L. Kirkpatrick, the editor, and the anonymous referees for their valuable comments on the manuscript. K.R. Swinnen held a Ph.D. grant from the Agency for Innovation by Science and Technology (IWT), Flanders, Belgium.

\section{LITERATURE CITED}

Barnes, D. M., and A. U. Mallik. 1996. Use of woody plants in construction of beaver dams in northern Ontario. Canadian Journal of Zoology 74:1781-1786.

Barnes, D. M., and A. U. Mallik. 1997. Habitat factors influencing beaver dam establishment in a northern Ontario watershed. Journal of Wildlife Management 61:1371-1377.

Beck, J. L., D. C. Dauwalter, K. G. Gerow, and G. D. Hayward. 2010. Design to monitor trend in abundance and presence of American beaver (Castor canadensis) at the national forest scale. Environmental Monitoring and Assessment 164:463-479.

Burchsted, D., M. Daniels, R. Thorson, and J. Vokoun. 2010. The river discontinuum: applying beaver modifications to baseline conditions for restoration of forested headwaters. BioScience 60:908-922.

Campbell-Palmer, R., D. Gow, R. Campbell, H. Dickinson, S. Girling, J. Gurnell., D. Halley, S. Jones and S. Lisle. 2016. The Eurasian beaver handbook: ecology and management of Castor fiber. Pelagic Publishing, Exeter, United Kingdom.

Collen, P., and R. J. Gibson. 2001. The general ecology of beavers (Castor spp.), as related to 
21 Swinnen \& Rutten et al. their influence on stream ecosystems and riparian habitats, and the subsequent effects on fish - a review. Reviews in Fish Biology and Fisheries 10:439-461.

Dalbeck, L., B. Lüscher, and D. Ohlhoff. 2007. Beaver ponds as habitat of amphibian communities in a central European highland. Amphibia-Reptilia 28:493-501.

De Visscher, M., J. Nyssen, J. Pontzeele, P. Billi, and A. Frankl. 2014. Spatio-temporal sedimentation patterns in beaver ponds along the Chevral river, Ardennes, Belgium. Hydrological Processes 28:1602-1615.

Guisan, A., and N. Zimmermann. 2000. Predictive habitat distribution models in ecology. Ecological Modelling 135:147-186.

Gurnell, A. M. 1998. The hydrogeomorphological effects of beaver dam-building activity. Progress in Physical Geography 22:167-189.

Halley, D., F. Rosell, and A. Saveljev. 2012. Population and distribution of Eurasian beaver (Castor fiber). Baltic Forestry 18:168-175.

Hartman, G., and A. Axelsson. 2004. Effect of watercourse characteristics on food-caching behaviour by European beaver, Castor fiber. Animal Behaviour 67:643-646.

Hartman, G., and S. Tornlov. 2006. Influence of watercourse depth and width on dambuilding behaviour by Eurasian beaver (Castor fiber). Journal of Zoology 268:127-131.

Hood, G. A., and D. G. Larson. 2014. Ecological engineering and aquatic connectivity: a new perspective from beaver-modified wetlands. Freshwater Biology 60:198-208.

Hothorn, T., K. Hornik, and A. Zeileis. 2006. Unbiased recursive partitioning: a conditional inference framework. Journal of Computational and Graphical Statistiscs 15:651-674.

Johnston, C. A., and R. J. Naiman. 1987. Boundary dynamics at the aquatic-terrestrial interface: the influence of beaver and geomorphology. Landscape Ecology 1:47-57.

Jones, C. G., J. H. Lawton, and M. Shachak. 1994. Organisms as ecosystem engineers. Oikos 69:373-386. 
22 | Swinnen \& Rutten et al.

Kellens, W., W. Vanneuville, E. Verfaillie, E. Meire, P. Deckers, and P. De Maeyer. 2013. Flood risk management in Flanders: past developments and future challenges. Water Resources Management 27:3585-3606.

Law, A., M. J. Gaywood, K. C. Jones, P. Ramsay, and N. J. Willby. 2017. Using ecosystem enigneers as tools in habitat restoration and rewilding: beaver and wetlands. Science of the Total Environment 605:1021-1030.

Lisle, S. 2003. The use and potential of flow devices in beaver management. Lutra 46:211216.

McComb, W. C., J. R. Sedell, and T. D. Buchholz. 1990. Dam-site selection by beavers in an eastern Oregon basin. Great Basin Naturalist 50:273-281.

Mitchell, J. K. 2003. European river floods in a changing world. Risk Analysis 23:567-574.

Nolet, B. A., A. Hoekstra, and M. M. Ottenheim. 1994. Selective foraging on woody species by beaver (Castor fiber) and its impact on riparian willow forest. Biological Conservation 70:117-128.

Nolet, B. A., and F. Rosell. 1998. Comeback of the beaver Castor fiber: an overview of old and new conservation problems. Biological Conservation 83:165-173.

Nummi, P., and A. Hahtola. 2008. The beaver as an ecosystem engineer facilitates teal breeding. Ecography 31:519-524.

Nyssen, J., J. Pontzeele, and P. Billi. 2011. Effect of beaver dams on the hydrology of small mountain streams: example from the Chevral in the Ourthe Orientale basin, Ardennes, Belgium. Journal of Hydrology 402:92-102.

Pahl-Wostl, C. 2006. The importance of social learning in restoring the multifunctionality of rivers and floodplains. Ecology and Society 11:10.

Pollock, M. M., G. M. Lewallen, K. Woodruff, C. E. Jordan, and J. M. Castro, editors. 2018. The beaver restoration guidebook: working with beaver to restore streams, wetlands, and 
23 | Swinnen \& Rutten et al.

floodplains. Version 2.01. United States Fish and Wildlife Service, Portland, Oregon, USA.

Rosell, F., O. Bozsér, P. Collen, and H. Parker. 2005. Ecological impact of beavers Castor fiber and Castor canadensis and their ability to modify ecosystems. Mammal Review $35: 248-276$.

Statbel. 2010. Structure of the population according to residence: surface and population density. Total population, on January 1 2010. Statistics of Belgium from the federal government. Statbel, Brussels, Belgium.

Stringer, A., and M. Gaywood. 2016. The impacts of beavers Castor spp. on biodiversity and the ecological basis for their reintroduction to Scotland, UK. Mammal Review 46:270283.

Suzuki, N., and W. C. McComb. 1998. Habitat classification models for beaver (Castor canadensis) in the streams of the Central Oregon Coast Range. Northwest Science $72: 102-110$.

Swinnen, K. R. R., D. Strubbe, E. Matthysen, and H. Leirs. 2017. Reintroduced Eurasian beavers (Castor fiber): colonization and range expansion across human-dominated landscapes 26:1863-1876.

Taylor, J., and R. D. Singleton. 2014. The evolution of flow devices used to reduce flooding by beavers: a review. Wildlife Society Bulletin 38:127-133.

Vriens, L., H. Bosch, G. De Knijf, S. De Saeger, P. Oosterlynck, R. Guelinckx, F. T’jollyn, M. Van Hove, and D. Paelinckx. 2011. De Biologische Waarderingskaart. Biotopen en hun verspreiding in Vlaanderen en het Brussels Hoofdstedelijk Gewest, Mededelingen van het Instituut voor Natuur- en Bosonderzoek INBO.M.2011.1. Instituut voor Natuuren Bosonderzoek, Brussel, 1-416.

Wright, J. P., C. G. Jones, and A. S. Flecker. 2002. An ecosystem engineer, the beaver, 
24 | Swinnen \& Rutten et al.

increases species richness at the landscape scale. Oecologia 132:96-101. 